Revista Brasil. Bot., V.31, n.2, p.195-207, abr.-jun. 2008

\title{
Fenologia reprodutiva, polinização e reprodução de Dipteryx alata Vogel (Leguminosae-Papilionoideae) em Mato Grosso do Sul, Brasil ${ }^{1}$
}

\author{
MATHILDE I. BACHIEGA OLIVEIRA ${ }^{2,3}$ e MARIA ROSÂNGELA SIGRIST ${ }^{2}$
}

(recebido: 23 de novembro de 2006; aceito: 27 de março de 2008)

\begin{abstract}
Reproductive phenology, pollination and reproduction of Dipteryx alata Vogel (Leguminosae-Papilionoideae) in Mato Grosso do Sul, Brazil). The reproductive biology of Dipteryx alata was studied from September/2004 through August/2006. Dipteryx alata is a tree that blooms during the rainy season (4-6 months) and fructification peak occurs in the dry season. There are annual variations in the intensity of flowering and fructification. The flowers are zygomorphic, papilionaceous, hermaphrodite, relatively small, odoriferous, diurnal and last up to 10 hours. The calyx has two petaloid lobules and the corolla is formed by the standard, wings and the petals of the keel. Pollen viability is $94.4 \%$. The stigma is covered by a pelicule that prevents pollen adherence and limits the spontaneous self-pollination. Nectar is produced in a chamber, in small quantity $(1.45 \mu \mathrm{L})$ and with concentration of $25 \%$. Dipteryx alata has keel flowers and the mechanism of pollination is intermediate between the explosive and valvular types. This species is alogamous, has late acting selfincompatibility and high rate of abortion $(\mathrm{ER}=0.45)$. The main pollinator is Xylocopa suspecta (16.6\% of visits), which visits legitimately the flowers and presents trap lining behavior, that promotes pollen flow between plants. Although the visitation rate of Pseudaugochlora graminea (15.3\%) and Apis mellifera (39.5\%) bees are relatively high, they are not good pollinators (pollination efficiency $=3.5$ and 0 , respectively), because they generally did not accomplish movement between plants. Apis mellifera robbed nectar in $45.5 \%$ of visits. The increasing of seed production in natural populations of $D$. alata depends on the maintenance of effective pollinators (solitary bees), and it is recommended the management of $A$. mellifera.
\end{abstract}

Key words - Apis mellifera, cumbaru, management, self incompatibility, Xylocopa suspecta

RESUMO - (Fenologia reprodutiva, polinização e reprodução de Dipteryx alata Vogel (Leguminosae-Papilionoideae) em Mato Grosso do Sul, Brasil). A biologia reprodutiva de Dipteryx alata foi estudada de setembro/2004 a agosto/2006. Dipteryx alata é arbórea, floresce na estação chuvosa (4-6 meses) e o pico de frutificação ocorre na estação seca. A espécie apresentou variação na intensidade de floração e frutificação entre os anos. As flores são zigomorfas, papilionáceas, hermafroditas, relativamente pequenas, odoríferas, diurnas e duram até 10 horas. O cálice possui dois lobos petalóides e a corola é formada pelo estandarte, alas e as pétalas da quilha. As anteras produzem pólen com 94,4\% de viabilidade. O estigma é recoberto por película que limita a autopolinização espontânea, impedindo a aderência do pólen. Néctar é armazenado em câmara, em pequena quantidade $(1,45 \mu \mathrm{L})$ e com concentração de $25 \%$. Dipteryx alata tem flores de quilha e possui mecanismo de polinização intermediário entre os tipos explosivo e valvular. Esta espécie é alógama, possui auto-incompatibilidade de ação tardia e elevada taxa de aborto $(\mathrm{ER}=0,45)$. Xylocopa suspecta $(16,6 \%$ das visitas) é o principal polinizador, pois visita legitimamente as flores e apresenta forrageamento do tipo linha-de-captura, que promove fluxo polínico entre as plantas. As abelhas Pseudaugochlora graminea (15,3\%) e Apis mellifera (39,5\%), apesar da alta taxa de visitação, não são bons polinizadores (eficiência de polinização de 3,5\% e $0 \%$, respectivamente), pois geralmente não realizam movimento entre as plantas. Apis mellifera pilha néctar em $45,5 \%$ das visitas realizadas. O aumento da produção de sementes em populações naturais de $D$. alata depende da manutenção dos polinizadores efetivos (abelhas solitárias), sendo recomendável o manejo da abelha exótica A. mellifera.

Palavras-chave - Apis mellifera, auto-incompatibilidade, cumbaru, manejo, Xylocopa suspecta

\section{Introdução}

Leguminosae é a terceira maior família dentre as Angiospermas, contando com 727 gêneros e

\footnotetext{
1. Parte da dissertação de Mestrado da primeira autora, Programa de Pós-Graduação em Biologia Vegetal da Universidade Federal do Mato Grosso do Sul.

2. Universidade Federal do Mato Grosso do Sul, Centro de Ciências Biológicas e da Saúde, Departamento de Biologia, Caixa Postal 549, 79070-900 Campo Grande, MS, Brasil.

3. Autor para correspondência: mathildeisa@hotmail.com
}

aproximadamente 19.325 espécies (Lewis et al. 2005). A importância econômica dos representantes desta família é indiscutível, pois muitos gêneros e espécies são utilizados na alimentação humana, como forrageiras, na recuperação de solos empobrecidos, na arborização urbana, bem como nas indústrias madeireira e química (Lewis et al. 2005).

Dentre as Leguminosae Papilionoideae, a polinização por abelhas é a mais freqüente, havendo evidências de que as flores zigomorfas e especializadas dos representantes desta subfamília sofreram forte pressão seletiva por parte 
deste grupo de insetos (Leppik 1966). Segundo Endress (1994), espécies de Papilionoideae com flores de pequena dimensão são polinizadas por ampla variedade de abelhas, enquanto aquelas com flores de maior tamanho são visitadas principalmente por abelhas de médio e grande porte dos gêneros Bombus, Centris e Xylocopa. Entretanto, há registros de Papilionoideae polinizadas por moscas (Medicago citrina (Font Quer) Greuter) (PérezBañón et al. 2003), aves (Camptosema, Erytrina), morcegos (Alexa, Mucuna) e mariposas (Camoensia) (Endress 1994), bem como a ocorrência de anemofilia em Ateleia (Janzen 1989 apud Endress 1994).

Quanto ao sistema de reprodução em Papilionoideae, Arroyo (1981) menciona auto-incompatibilidade em $22,1 \%$ das espécies investigadas, proporção baixa se comparada com Caesalpinioideae (62,3\%) e Mimosoideae (66,7\%) (Lopez et al. 1999). Autoincompatibilidade de ação tardia é registrada para diversas espécies arbóreas de Papilionoideae (Seavey \& Bawa 1986), apresentando diferentes mecanismos de ação, desde a inibição ovariana (Bernardello et al. 2004) até rejeição pós-zigótica (Gibbs \& Sassaki 1998). Além disso, algumas espécies autocompatíveis apresentam mecanismos para evitar ou reduzir a autopolinização como a presença de película estigmática que impede a germinação do pólen (HeslopHarrison \& Heslop-Harrison 1983).

O gênero Dipteryx apresenta 12 espécies distribuídas nas Américas do Sul e Central, sendo a maioria amazônica, mas com duas espécies ocorrentes no Panamá e Honduras e uma em áreas secas do Brasil Central (Lewis et al. 2005). Diversas espécies deste gênero apresentam múltiplos usos, destacando-se D. alata e D. odorata (Aubl.) Willd. (Almeida et al. 1998, Lewis et al. 2005). Para o gênero Dipteryx há registro de polinização por abelhas de médio e grande porte, bem como alogamia obrigatória (Perry \& Starrett 1980, Seavey \& Bawa 1986).

Dipteryx alata Vogel é arbórea, conhecida como baru ou cumbaru, cuja semente no Mato Grosso do Sul e em outros estados do Centro-Oeste é beneficiada e comercializada "in natura", torrada ou sob a forma de farinha, gerando renda para diversas comunidades regionais que vivem em áreas de cerrado (Silva \& Egito 2005). No Brasil, uma tonelada de sementes não beneficiadas de cumbaru vale aproximadamente $386 \mathrm{mil}$ dólares (IPEF 2004), sendo muito valorizada no mercado consumidor externo. Apesar da importância econômica indiscutível de D. alata, dados sobre a fenologia, polinização e reprodução desta espécie são escassos e/ou pouco conclusivos. Pott \& Pott (1994) descrevem-na como “muito apícola". Perez Filho \& Dorval (1995 apud Thum \& Costa 1998/99) observaram insetos das ordens
Diptera, Hymenoptera e Lepidoptera como visitantes florais do cumbaru, sendo que 50,4\% dos insetos coletados foram indivíduos de Apis mellifera. Segundo Almeida et al. (1998), o cumbaru floresce de novembro a fevereiro e frutifica de janeiro a março, excepcionalmente até julho nos cerrados do Centro-Oeste. Entretanto, no Maranhão, Bulhão \& Figueiredo (2002) registraram floração até março e frutificação até agosto. A dispersão dos frutos desta espécie parece ocorrer na estação seca (Pott \& Pott 1994, Bulhão \& Figueiredo 2002).

Considerando o exposto acima, neste trabalho foram investigadas a fenologia, polinização e reprodução de Dipteryx alata com o intuito de fornecer subsídios para otimizar a coleta e a produção de frutos e sementes, bem como para a conservação da espécie e o manejo de seus polinizadores em áreas naturais. Tais objetivos vêm de encontro aos objetivos da "Estratégia Global para a Conservação de Plantas" (Secretaria da Conservação Sobre Diversidade Biológica 2006), aprovada pelos países signatários da "Convenção sobre Diversidade Biológica", da qual o Brasil é parceiro, e que prevê estudos para a conservação de espécies vegetais com importância direta para sociedades humanas e o desenvolvimento de meios de subsistência baseados no uso sustentável destas espécies.

\section{Material e métodos}

Este estudo foi desenvolvido de setembro/2004 a agosto/ 2006 em duas áreas que fazem parte do campus da Universidade Federal de Mato Grosso do Sul (UFMS), em Campo Grande, MS $\left(20^{\circ} 27^{\prime}\right.$ S e $54^{\circ} 37^{\prime} \mathrm{W}, 530 \mathrm{~m}$ de altitude): (i) remanescente urbano de cerrado pertencente à RPPN da UFMS, com cerca de 36,5 ha e vegetação composta principalmente por cerrado e cerradão; (ii) porção arborizada do campus, constituída por agrupamentos de espécies vegetais, pré-existentes ou plantadas, dispersas entre os gramados, construções e alamedas. As duas áreas distam entre si cerca de quatro quilômetros, sendo as plantas da segunda área remanescentes da vegetação que existia anteriormente. A população estudada é constituída por 24 plantas adultas (com três a 12 metros de altura), sendo 20 situadas na área de cerrado e quatro indivíduos remanescentes na área arborizada.

O clima da região é do tipo Tropical Chuvoso de Savana (subtipo Aw) (Köppen 1948) com inverno seco e verão chuvoso. A precipitação média anual é de $1.532 \mathrm{~mm}$, a umidade relativa é geralmente baixa, raramente atingindo $80 \%$ e as temperaturas médias anuais ficam entre 20 e $22{ }^{\circ} \mathrm{C}$ (Embrapa-CNPGC 1985).

No campo foram efetuadas observações sobre o tipo e a disposição das inflorescências nas plantas, bem como quantificado o número de flores abertas diariamente por 
inflorescência $(n=15)$ e por planta $(n=3)$. As observações sobre floração e frutificação de Dipteryx alata foram realizadas de setembro/2004 a agosto/2006, nos 20 indivíduos da área de cerrado, sendo estimado mensalmente o número de botões, flores (aberta, acessível ao visitante e/ou receptiva à polinização até a murcha), frutos imaturos (com aumento de cerca de três vezes o tamanho do ovário, equivalendo a aproximadamente quatro $\mathrm{cm}$ de comprimento) e frutos desenvolvidos (maior que quatro $\mathrm{cm}$, com coloração acastanhada e em fase de dispersão). A quantificação das fenofases foi realizada a partir da metodologia proposta por Fournier (1974), a qual avalia individualmente as fenofases, utilizando escala intervalar semi-quantitativa de cinco categorias (zero a quatro) e intervalo de $25 \%$ entre cada categoria. Mensalmente foi feita a soma dos valores obtidos para todos os indivíduos da população estudada, dividindo-se pelo valor máximo possível (número de indivíduos multiplicado por quatro). Este valor, que corresponde a uma proporção, é multiplicado por 100, para transformar-se em valor percentual.

Registros sobre a flor, tais como forma, morfometria ( $n=25$ flores), coloração das partes florais, percepção de odor, localização e tipo de recurso oferecido aos visitantes foram registrados no campo e/ou laboratório a partir de flores frescas e/ou fixadas em álcool 70\%, coletadas em cinco indivíduos. A presença de osmóforos nas estruturas florais foi verificada utilizando-se vermelho neutro (modificada de Dafni et al. 2005). A viabilidade do pólen foi determinada pela coloração com carmin acético (Dafni et al. 2005), a partir de 15 botões em pré-antese, provenientes de três plantas. Para cada flor foram quantificados 200 grãos de pólen/lâmina misturando-se os grãos de todas as anteras. A receptividade do estigma foi verificada no campo e laboratório através da observação do aspecto da superfície estigmática, utilizando lupa especial ("Lupenbrille”) e estereomicroscópio, respectivamente.

Os eventos de biologia floral foram acompanhados em 52 flores marcadas em cinco indivíduos, da pré-antese até a murcha. A concentração de solutos e o volume de néctar acumulado até aproximadamente às $10 \mathrm{~h} 00$ foram medidos com refratômetro de bolso e microcapilares, respectivamente (Dafni et al. 2005) em 14 flores ensacadas na pré-antese.

Nos estudos sobre o sistema reprodutivo foram feitos experimentos de polinizações manuais (autopolinização e polinização cruzada) em flores previamente ensacadas e não emasculadas. Alguns botões foram mantidos intactos, ou seja, sem tratamento após o ensacamento, para verificar a ocorrência de autopolinização espontânea. Flores não ensacadas foram marcadas a fim de avaliar o desenvolvimento de frutos em condições naturais (controle). Em cada inflorescência foi realizado número limitado de tratamentos (máximo cinco flores) e em todos os experimentos foram utilizadas apenas flores da região basal da inflorescência, uma vez que, segundo Bawa \& Webb (1984), nas Papilionoideae a probabilidade de formação de frutos nesta região parece ser maior. A partir dos resultados obtidos foram calculados o índice de auto-incompatibilidade (ISI $=\%$ frutos formados por flores autopolinizadas manualmente / \% flores submetidas à polinização cruzada) e a eficácia reprodutiva $(\mathrm{ER}=\%$ frutos formados em condições naturais $/ \%$ frutos formados por polinização cruzada) (sensu Sobrevila \& Arroyo 1982). O desenvolvimento dos frutos foi acompanhado inicialmente a cada três dias; após um mês foi monitorado semanalmente e depois de dois meses, quinzenalmente. As sementes oriundas dos tratamentos foram removidas dos frutos, seccionadas ao meio e colocadas em solução aquosa de cloreto de tetrazólio a $0,5 \%$ por uma hora a fim de verificar a viabilidade do embrião (modificado de Velten \& Garcia 2005). Foram consideradas viáveis sementes que apresentaram embrião corado de vermelho claro. O percentual de frutos e sementes produzidas em cada tratamento foi analisado através do teste de $\chi^{2}$ ao nível de significância de 5\% (Zar 1999).

$\mathrm{O}$ estudo do sistema reprodutivo foi complementado com observações de crescimento de tubos polínicos. Para tanto, polinizações manuais (auto e cruzada) foram realizadas no campo ( $n=30$ flores por tratamento) e em laboratório, em gerbox, utilizando-se gelatina sem sabor como suporte para os gineceus $(n=15)$. Após as polinizações, os gineceus foram fixados em FAA em etanol 70\%, a intervalos de oito, 16 e 24 horas ( $n=15$ flores por horário, por tratamento), sendo depois estocados em álcool 70\%. Posteriormente, foram diafanizados segundo método ligeiramente modificado de Strittmatter (1973), utilizando-se a seguinte seqüência: álcool $95 \%$ a $100{ }^{\circ} \mathrm{C}$ por oito minutos; 12 minutos em $\mathrm{NaOH}$ $5 \%$ a $100{ }^{\circ} \mathrm{C}$; hipoclorito $20 \%$ por cerca de 60 minutos à temperatura ambiente; entre cada etapa, o material vegetal foi lavado inúmeras vezes em água destilada. Posteriormente, os gineceus foram submetidos à técnica de microscopia de fluorescência (Martin 1959). O crescimento dos tubos polínicos em cada tratamento para cada horário foi comparado e o percentual de penetração dos óvulos foi avaliado através da aplicação do teste de $\chi^{2}$ ao nível de significância de 5\% (Zar 1999).

A observação dos visitantes florais foi efetuada entre 6 h00 e 16 h00, em sete plantas, durante 15 dias não consecutivos, totalizando 74 horas de observações. O comportamento dos animais visitantes às flores foi registrado por meio de observações visuais diretas, à vista desarmada e/ou com auxílio de binóculo e por fotografias. Foi anotado o tipo de visitante, o horário de chegada do mesmo à planta e a frequiência de visita na planta (= número total de visitas registradas durante o período de observação). Como visita entende-se o período entre a chegada ou (novo) avistamento do visitante até a saída/perda de avistamento do visitante floral à planta focal, durante o qual as flores foram continuamente visitadas. Para alguns visitantes a duração das visitas às flores foi cronometrada. Quando possível, os insetos foram coletados com auxílio de câmaras mortíferas, frasco aspirador ou saco plástico. Em seguida, foram acondicionados individualmente em potes plásticos, devidamente etiquetados com dia e hora de coleta. Foram congelados, medidos e alguns deles foram analisados sob 
estereomicroscópio para verificar o local de deposição de pólen no corpo. Posteriormente, foram montados, etiquetados e encaminhados a especialistas para identificação. A eficiência de polinização (EP), ou seja, taxa de frutificação após uma visita (cf. Spears 1983) foi avaliada para dois dos três visitantes mais freqüentes (abelhas Apis mellifera e Pseudaugochlora graminea). Posteriormente a porcentagem de frutos formados foi analisada utilizando-se o teste de $\chi^{2}$ ao nível de significância de 5\% (Zar 1999). Para Xylocopa suspecta a EP não foi avaliada, pois a proximidade do observador afugentava os indivíduos desta espécie.

Material testemunho de D. alata está depositado no Herbário da Universidade Federal de Mato Grosso do Sul, Campo Grande (CGMS 15303).

\section{Resultados}

Em ambas as áreas estudadas, as plantas de Dipteryx alata ocorrem isoladas ou reunidas em agrupamentos com até três indivíduos. Durante o estudo, as plantas floresceram sincronicamente na estação chuvosa, por quatro a seis meses (figura 1A). No primeiro período de observação (2004) a floração ocorreu de outubro a janeiro, com pico em novembro, enquanto no segundo período (2005-2006) o florescimento iniciou em novembro e estendeu-se até abril, com elevada produção de botões e flores em fevereiro (figura 1A). A frutificação iniciou dois meses após o começo da floração e estendeu-se até o próximo evento reprodutivo, que iniciou em novembro/2005, de modo que nas plantas há frutos desenvolvidos, em dispersão, praticamente o ano todo (figura 1B). O pico de frutificação ocorreu na estação seca, principalmente de março a julho em 2005 e de maio a agosto em 2006. No segundo período de observação, houve redução na intensidade de floração e frutificação em relação ao primeiro (figura 1).

As inflorescências são panículas terminais que contém em média 116 botões. Diariamente abriram em média 17 flores $( \pm 12,1)$ por inflorescência e 2.350 flores ( \pm 658 ) por indivíduo. As flores de D. alata são hermafroditas, papilionáceas, zigomorfas (figura 2), pentâmeras, diplostêmones e relativamente pequenas ( $1,30 \pm 0,19 \mathrm{~cm}$ de comprimento). O cálice é esverdeado, forma um tubo que recobre a porção basal da corola e possui dois lobos petalóides em forma de asas (figura 2), sendo os três restantes reduzidos a pequenos dentes. A corola é formada pelo estandarte, as alas e as pétalas da quilha, que são ungüiculadas e podem ser rosadas a esbranquiçadas; a porção mediana do estandarte pode ou não apresentar mácula de cor rosa. O estandarte ocupa posição superior em relação às outras pétalas; possui

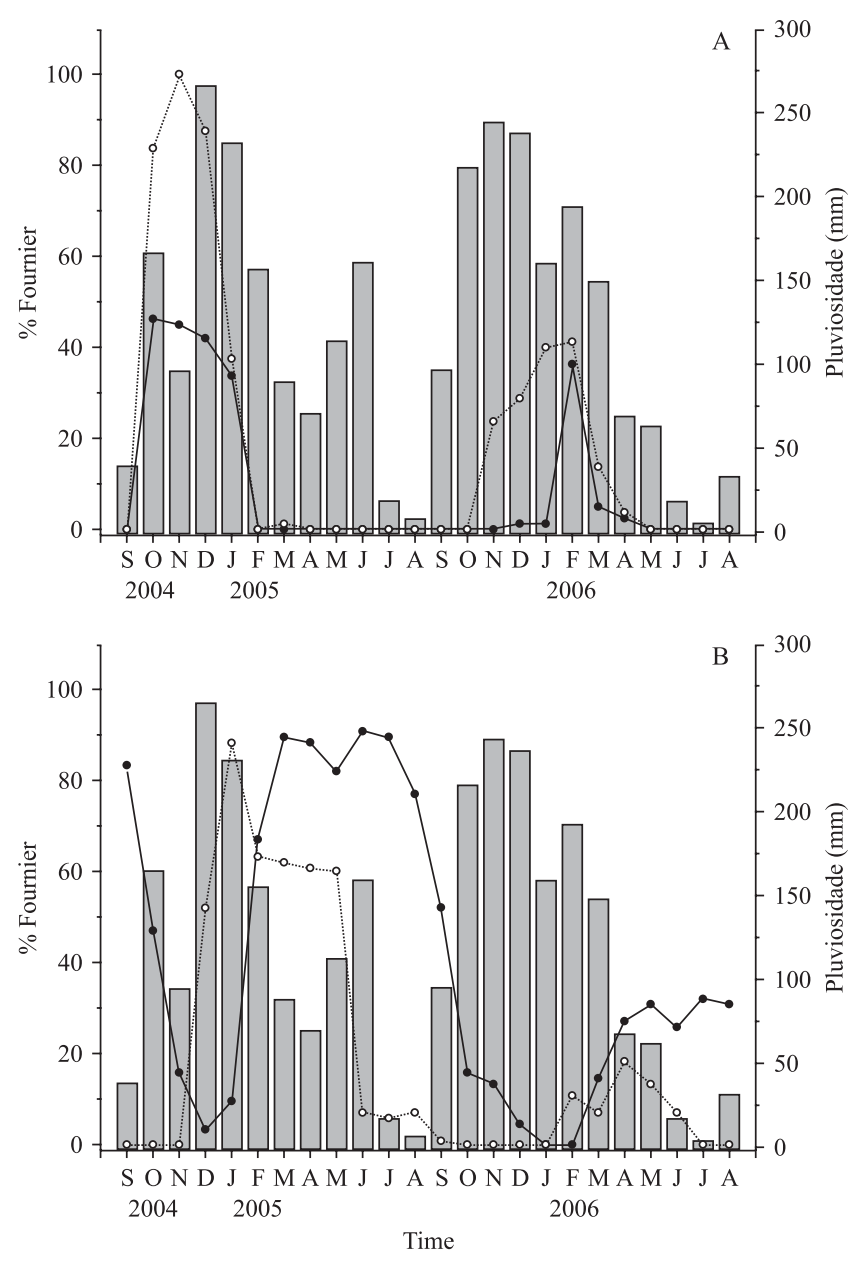

Figura 1. Fenologia de floração (A) e frutificação (B) de Dipteryx alata. Diagramas mostrando a intensidade de produção de botões $(-\mathrm{O}-)$ e flores $(-\bullet-)(\mathrm{A})$, frutos imaturos (-O-) e desenvolvidos (-๑-) (B) em uma população de Dipteryx alata em remanescente de cerrado, em Campo Grande, Mato Grosso do Sul. As barras correspondem à pluviosidade do período.

Figure 1. Flowering (A) and fruit set (B) of Dipteryx alata. Diagrams showing the intensity of bud production (-O-) and flowers (--) (A), immature fruits (-O- ) and developed fruits (- - ) (B) in a population of Dipteryx alata in a remnant of "cerrado", in Campo Grande, Mato Grosso do Sul. The bars correspond to the rain fall for each period.

limbo amplo, refletido e com sulco mediano (figura 2) e unha alargada, que envolve o terço inferior das alas e quilha. As alas são livres entre si, envolvem parcialmente as pétalas da quilha, apresentam unha estreita e porção superior do limbo com lamelas esculpidas na superfície (figura 10). As pétalas da quilha envolvem as estruturas sexuais, sendo auriculadas e adnadas na porção inferior, com unhas estreitas que ficam parcialmente encobertas 
pelas unhas das alas. As alas e as pétalas da quilha se encaixam por dobras localizadas na porção mediana destas pétalas.

O androceu é heterodínamo e monadelfo, com filetes formando uma bainha estaminal fendida longitudinalmente na porção superior, presa basalmente ao receptáculo e que envolve o gineceu. As anteras são dorsifixas, rimosas e apresentam pólen com viabilidade em torno de $94,4 \%$ $( \pm 0,78 \%)$. O gineceu é estipitado, unicarpelar, uniovulado e possui estigma posicionado junto das
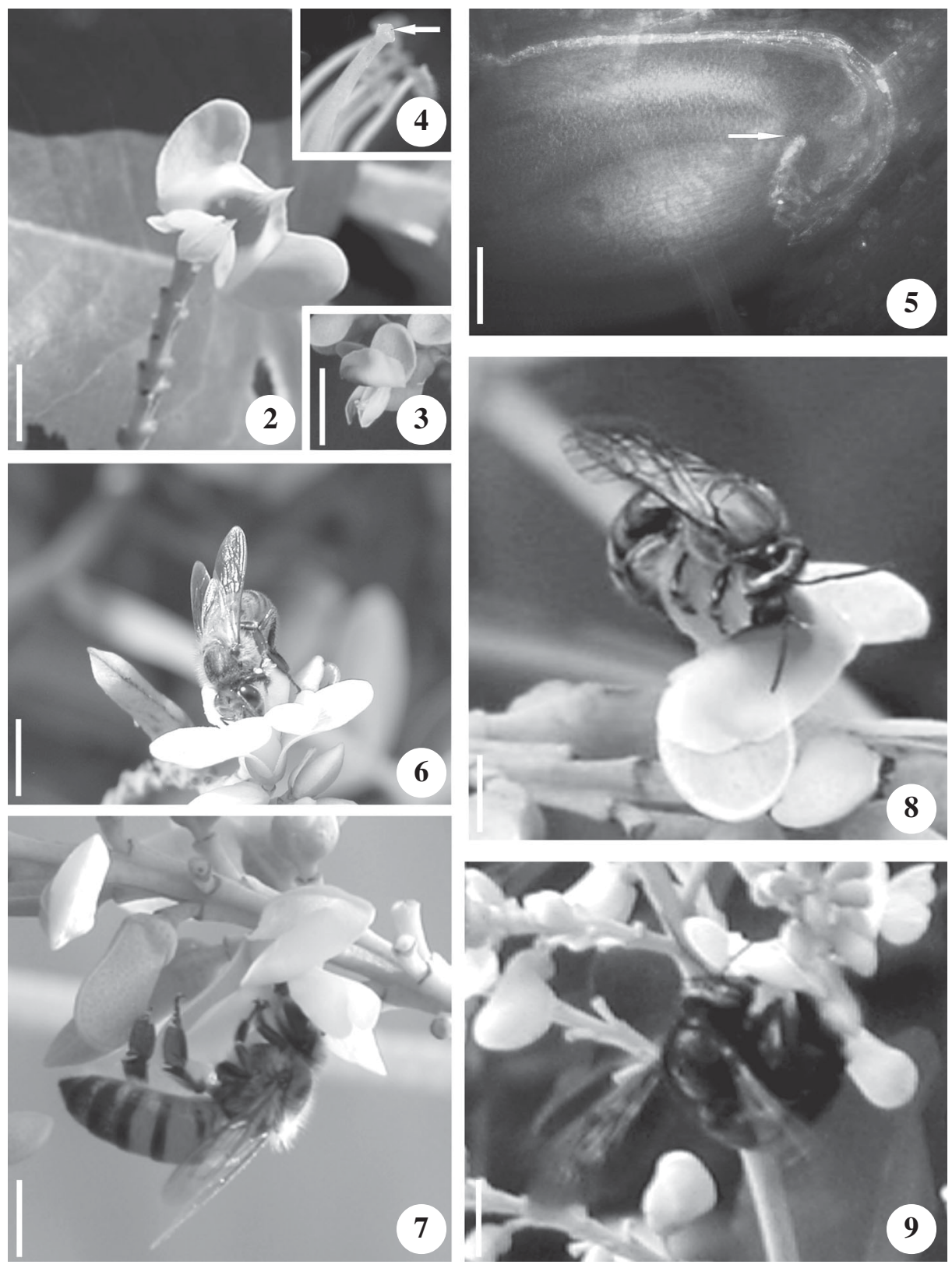

Figuras 2-9. Flor de Dipteryx alata não visitada (2) e com estruturas sexuais expostas após visita legítima (3). Estigma (seta) situado próximo das anteras (4). Tubo polínico atingindo o óvulo (seta) 24 horas após a autopolinização manual (5). Abelha Apis mellifera em visita legítima, contatando anteras e estigma com a porção ventral do corpo (6) ou com a cabeça (7). Pseudaugochlora graminea (8) e Xylocopa suspecta (9) em visita legítima à flor. Barra $=1 \mathrm{~cm}$.

Figure 2-9. Non-visited flowers of Dipteryx alata (2), flower with exposed sexual organs after legitimate visitation (3). Stigma (arrow) placed near the anthers (4). Pollen tube reaching the ovule (arrow) 24 hours after hand self-pollination (5). Apis mellifera in a legitimate visit, contacting anthers and stigma with the ventral portion of the body (6) or with head (7), Pseudaugochlora graminea (8) and Xylocopa suspecta (9) in a legitimate visit. Bar $=1 \mathrm{~cm}$. 
anteras (figura 4) e recoberto por fina película esbranquiçada que retêm líquido transparente e viscoso. Néctar é produzido por tecido que reveste o receptáculo floral, o qual forma uma câmara (figura 11) onde o néctar fica acumulado em pequena quantidade $1,45 \mu \mathrm{L}( \pm 0,4)$ e com concentração de solutos em torno de $25 \%$.

As flores abrem antes das $6 \mathrm{~h} 00$ e duram aproximadamente dez horas. Desde o início da antese há produção de néctar, as anteras estão abertas e o estigma encontra-se cheio de líquido e geralmente recoberto por grãos de pólen. A abertura da flor caracteriza-se pelo afastamento e posicionamento dos lobos petalóides do cálice e pela distensão e reflexão do estandarte, permitindo a exposição das alas e de parte das pétalas da quilha. Ao abrirem, as flores exalam odor adocicado, que é produzido por osmóforos situados na porção inferior das alas, junto às lamelas. Nas flores intensamente visitadas, após quatro a cinco horas da abertura, o estigma continua receptivo e praticamente não há mais pólen nas anteras, ocorrendo queda das alas e quilha e, eventualmente, do
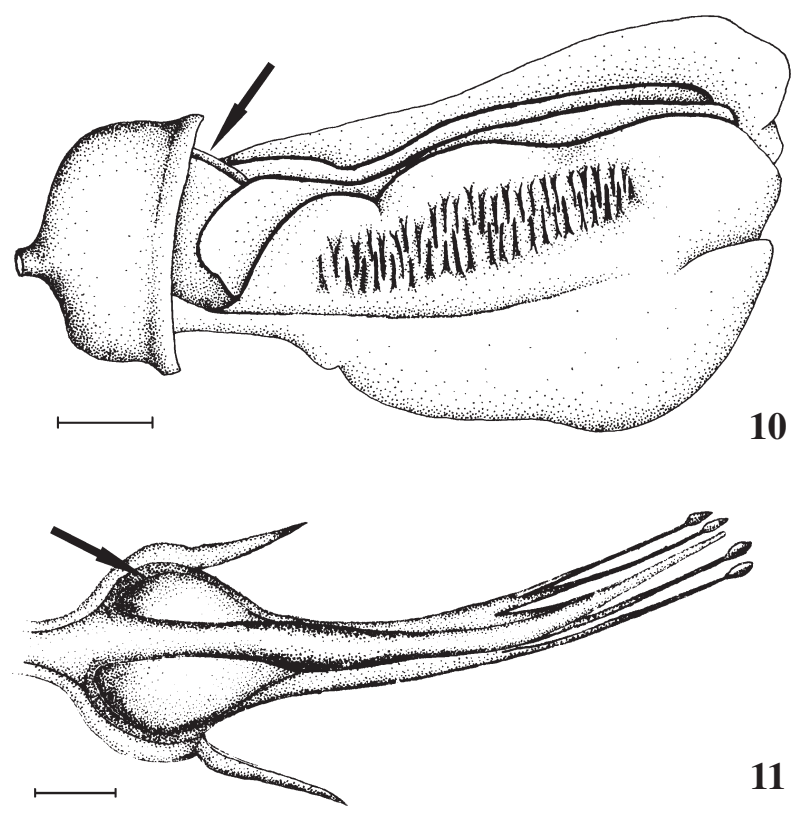

Figuras 10-11. Esquemas da flor de Dipteryx alata. 10. Estandarte removido, evidenciando a entrada da câmara nectarífera, formada pela bainha estaminal (seta), e as lamelas das alas. 11. Corte longitudinal mediano, após remoção da corola, mostrando a câmara nectarífera (seta). Barra $=1 \mathrm{~mm}$.

Figure 10-11. Schemes of Dipteryx alata flower. 10. Removed standard, showing the entrance of nectariferous chamber (arrow) and the lamellae of wings. 11. Median longitudinal section, after removal of corolla, showing nectariferous camera (arrow). Bar $=1 \mathrm{~mm}$. estandarte. Em flores que recebem poucas visitas, a queda das pétalas ocorre por volta das $16 \mathrm{~h} 00$.

Em D. alata não houve formação de frutos após autopolinização espontânea e manual (ISI $=0$, tabela 1). A taxa de frutificação após polinização cruzada foi baixa, não havendo diferença significativa $\left(\chi^{2}=5,11\right.$, $P>0,05)$ daquela observada em condições naturais $(\mathrm{ER}=0,45$, tabela 1$)$, devido ao reduzido número de frutos formados em ambos os casos. Após uma semana, em todos os tratamentos, mais de $50 \%$ das flores abortaram, embora este percentual seja maior nas flores autopolinizadas (tabela 2), as quais já apresentavam ligeiro aumento no tamanho dos ovários. Flores autopolinizadas manualmente demoraram mais tempo para abortar quando comparadas àquelas submetidas à autopolinização espontânea (tabela 2). Após cerca de dois meses e meio, os frutos obtidos nos tratamentos de polinização cruzada e controle amadureceram e apresentaram sementes com embriões viáveis.

Em flores submetidas à autopolinização manual e polinização cruzada, após oito horas os tubos polínicos atingiram o terço superior do estilete e, após 16 e 24 horas, maior número de óvulos haviam sido penetrados por tubos polínicos oriundos de polinização cruzada $(n=9$ e 11, respectivamente) quando comparado com os de autopolinização ( $n=6$ e 8 , respectivamente) (figura 5), embora não haja diferença significativa $(P>0,05)$.

Tabela 1. Resultados dos experimentos de sistema reprodutivo de Dipteryx alata e a eficiência de polinização das abelhas Apis mellifera e Pseudaugochlora graminea em Campo Grande, Mato Grosso do Sul (no = número; ISI = índice de auto-incompatibilidade; $\mathrm{ER}=$ eficácia reprodutiva).

Table 1. Results of breeding system experiments of Dipteryx alata and the pollination efficiency of Apis mellifera and Pseudaugochlora graminea bees in Campo Grande, Mato Grosso do Sul ( $\mathrm{n}^{\mathrm{o}}=$ number; ISI = self-incompatibility index; $\mathrm{ER}=$ reproductive efficacy).

$\%$ (no frutos / $\mathrm{n}^{\mathrm{o}}$ flores)

\section{SISTEMA REPRODUTIVO}

Autopolinização espontânea

Autopolinização manual

$0 \quad(0 / 47)$

Polinização cruzada

Condições naturais

$5,60(3 / 54)$

ISI

$2,50(1 / 40)$

ER

0,00

0,45

EFICIÊNCIA DE POLINIZAÇÃO

Apis mellifera

$\begin{array}{ll}0 & (0 / 25)\end{array}$

Pseudaugochlora graminea
$3,50(1 / 28)$ 
Tabela 2. Percentual de aborto de frutos em população de Dipteryx alata ao longo de 45 dias, em flores submetidas a polinizações manuais (autopolinização e polinização cruzada), autopolinização espontânea e sob polinização em condições naturais (controle).

Table 2. Percentage of fruits aborted of a population of Dipteryx alata during 45 days, in flowers submitted to hand pollinations (self- and cross-pollination), spontaneous self-pollination and under pollination in natural conditions (control).

\begin{tabular}{lcccc}
\hline \multirow{2}{*}{$\begin{array}{l}\text { Dias após a } \\
\text { polinização }\end{array}$} & $\begin{array}{c}\text { Tratamentos (\%) } \\
\text { Autopolinização } \\
\text { espontânea }\end{array}$ & $\begin{array}{c}\text { Autopolinização } \\
\text { manual }\end{array}$ & $\begin{array}{c}\text { Polinização } \\
\text { cruzada }\end{array}$ & $\begin{array}{c}\text { Polinização } \\
\text { natural }\end{array}$ \\
\hline 1 & 0 & 0 & 0 & 0 \\
4 & 91,5 & 70,5 & 61,0 & 40,0 \\
7 & 96,0 & 83,0 & 68,5 & 52,5 \\
10 & 98,0 & 85,0 & 74,0 & 75,0 \\
17 & 100 & 96,0 & 83,5 & 90,0 \\
24 & - & 98,0 & 83,5 & 92,5 \\
32 & - & 100 & 91,0 & 92,5 \\
45 & - & - & 92,5 & 92,5 \\
\hline
\end{tabular}

Entretanto, após 24 horas os tubos polínicos oriundos de polinização cruzada haviam penetrado o óvulo $(n=11)$ ou atingido o ovário $(n=4)$, enquanto nas flores autopolinizadas quase metade dos tubos pararam na porção final do estilete $(n=7)$.

Abelhas, vespas, moscas, borboletas e beija-flores foram os visitantes amostrados nas flores de $D$. alata (tabela 3). A maioria foi observada nas duas áreas, exceto moscas e borboletas, amostradas somente na área urbana, enquanto as vespas, o beija-flor Hylocharis chrysura e as abelhas Ceratina sp. e Paratetrapedia sp. foram registrados apenas no cerrado. Os himenópteros, principalmente abelhas $(90,2 \%)$, foram responsáveis pela maioria das visitas $(97,3 \%)$ que ocorreram principalmente no período matutino, entre $8 \mathrm{~h} 00$ e $11 \mathrm{~h} 00$ (figura 12 ). As abelhas Apis mellifera (freqüência de $39,5 \%$ do total de visitas registradas), Xylocopa suspecta $(16,6 \%)$ e Pseudaugochlora graminea (15,3\%) totalizaram 71,3\% das visitas (tabela 3 ), sendo que A. mellifera visitou as flores ao longo do dia, com pico durante parte da manhã e da tarde (figura 12). Xylocopa suspecta e P. graminea concentraram as visitas nas primeiras classes de horário (06h00-10h00) (figura 12).

Apis mellifera, em 20\% dos registros, e P. graminea visitaram as flores do seguinte modo: em vôo aproximavamse da flor e pousavam sobre as alas e as pétalas da quilha posicionando o primeiro par de pernas junto à base do estandarte ou alas e o segundo par na porção lamelada das alas (A. mellifera - figura 6) ou abaixo desta região (P. graminea - figura 8$)$. Simultaneamente exerciam pressão sobre o estandarte com a cabeça para inserir as peças bucais na região de contato do estandarte e as demais pétalas, ocasionando o deslocamento das alas e pétalas da quilha, que ao serem pressionadas, possibilitavam a exteriorização das anteras e estigma, os quais contatavam a porção ventral do tórax das abelhas. Concomitantemente introduziam a probóscide e, utilizando a língua, afastavam as aurículas das pétalas da quilha, acessando a câmara nectarífera. Após alguns segundos (4-5 seg. para $P$. graminea; 4-12 seg. para $A$. mellifera), recuavam e, ao saírem da flor, tocavam as anteras com a cabeça e às vezes com o primeiro par de pernas, pois anteras e estigma não retornam à posição original, permanecendo a quilha total ou parcialmente aberta (figura 3). Por vezes, antes de sair da flor, realizavam a limpeza do corpo com o auxílio do primeiro e segundo pares de pernas. Posteriormente, visitavam geralmente outras flores da mesma (A. mellifera) ou de outra inflorescência ( $P$. graminea), podendo permanecer por pelo menos 60 minutos na mesma planta.

Na maioria das visitas (80\%), Apis mellifera visitou as flores de outras maneiras, legítimas $(54,5 \%)$ ou não legítimas (45,5\%): (i) pousava sobre o estandarte, virava e posicionava-se defronte esta pétala, usando as alas e quilha como apoio. Ao realizar esse comportamento, promovia o desprendimento de alas e quilha, de modo que as estruturas sexuais ficavam expostas e entravam em contato com a porção ventral e/ou pernas da abelha (12,5\% das visitas); (ii) pousava sobre um dos lobos da sépala e/ou limbo do estandarte ou posicionava-se 
Tabela 3. Visitantes florais de Dipteryx alata, comprimento total aproximado do corpo (CTA) das abelhas, vespas e moscas coletadas, freqüência de visitas e atuação na polinização (n⿳⺈ = número).

( $\mathrm{PP}=$ polinizador principal: posicionamento intrafloral adequado (legítimo), realiza visita entre plantas e frequiência de visita legítima $\geq 15 \%$; PS = polinizador secundário: posicionamento intrafloral adequado, eventualmente realiza visita entre plantas e freqüência de visita legítima $\geq 15 \%$; $\mathrm{PE}=$ polinizador eventual: posicionamento intrafloral adequado, eventualmente realiza visita entre plantas e frequiência de visita legítima $<15 \%$; PI = pilhador: não contata os órgãos sexuais ao tomar néctar e/ou frequiência de visita $<3 \%$ )

Table 3. Floral visitors of Dipteryx alata, approximate body length (CTA) of collected bees, wasps and flies, frequency of visits and performance in pollination ( $\mathrm{n}^{\mathrm{o}}=$ number).

( $\mathrm{PP}=$ main pollinator: suitable intrafloral position, accomplish visits between plants and frequency of legitimate visit $\geq 15 \%$; PS = secondary pollinator: suitable intrafloral position, sometimes accomplish visits between plants and frequency of legitimate visit $\geq 15 \%$; $\mathrm{PE}=$ eventual pollinator: suitable intrafloral position, sometimes accomplish visits between plants and frequency of legitimate visit $<15 \%$; PI = nectar robber: don't get in contact with sexual organs when drinking nectar and/or frequency of visit $<3 \%$ )

\begin{tabular}{|c|c|c|c|}
\hline VISITANTES (n) & $\begin{array}{c}\text { CTA } \\
(\text { média } \pm s) \\
(\mathrm{cm})\end{array}$ & $\begin{array}{c}\text { Freqüência } \\
\text { de visitas } \\
\mathrm{n}^{\mathrm{o}} /(\%)\end{array}$ & $\begin{array}{l}\text { Atuação na } \\
\text { polinização }\end{array}$ \\
\hline
\end{tabular}

\section{INSETOS}

AbelHas

Apidae

Apis mellifera (Linnaeus 1758) (6)

Exomalopsis sp. (4)

Paratrigona lineata (Lepeletier, 1836) (3)

Paratetrapedia sp. (1)

Trigona branneri Cockerell, 1912 (3)

Xylocopa suspecta Moure \& Camargo, 1988 (7)

Halictidae

Augochloropsis callichroa (Cockerell, 1900) (1)

Augochloropsis aff. cupreola (Cockerell, 1900) (1)

Pseudaugochlora graminea (Fabricius, 1804) (7)

Ceratina (Crewella) sp.1 (1)

$\begin{array}{crlr}1,05 \pm 0,05 & 121 & (39,5)^{*} & \text { PS/P } \\ 0,67 \pm 0,05 & 11 & (3,6) & \text { PI } \\ 0,40 & 12 & (3,9) & \text { PI } \\ - & 2 & (0,7) & \text { PI } \\ 0,70 & 20 & (6,5) & \text { PI } \\ 2,35 \pm 0,22 & 51 & (16,6) & \text { PP } \\ & & & \\ 0,76 & 2 & (0,7) & \text { PI } \\ 1,10 & 10 & (3,3) & \text { PE } \\ 1,06 \pm 0,19 & 47 & (15,3) & \text { PS } \\ 0,58 & 1 & (0,3) & \text { PI }\end{array}$

VESPAS

Vespidae

Nectarina sp. (3)

$0,90 \pm 0,05$

$14(4,6)$

$0,78 \pm 0,02$

$3(1,0)$

PI

Polybia sp. (2)

BORBOLETAS

Hesperiidae

Urbanus sp.

Lycaenidae

$\begin{array}{lll}- & 1(0,3) & \text { PI } \\ - & 1(0,3) & \text { PI }\end{array}$

Moscas

Syrphidae 1 (1)

Syrphidae 2 (2)

$\begin{array}{cll}0,98 & 2(0,7) & \text { PI } \\ 1,10 \pm 0,14 & 1(0,3) & \text { PI }\end{array}$

AVES

BEIJA-FLORES (Trochilidae)

Chlorostilbon aureoventris (d'Orbigny \& Lafresnaye, 1838)

$\begin{array}{lll}- & 3(1,0) & \text { PI } \\ - & 5(1,6) & \text { PI }\end{array}$

Hylocharis chrysura (Shaw, 1812)

$*$ visita legítima/legitimate visit $=21,5 \%$; visita ilegítima/illegitimate visit $=18 \%$. 


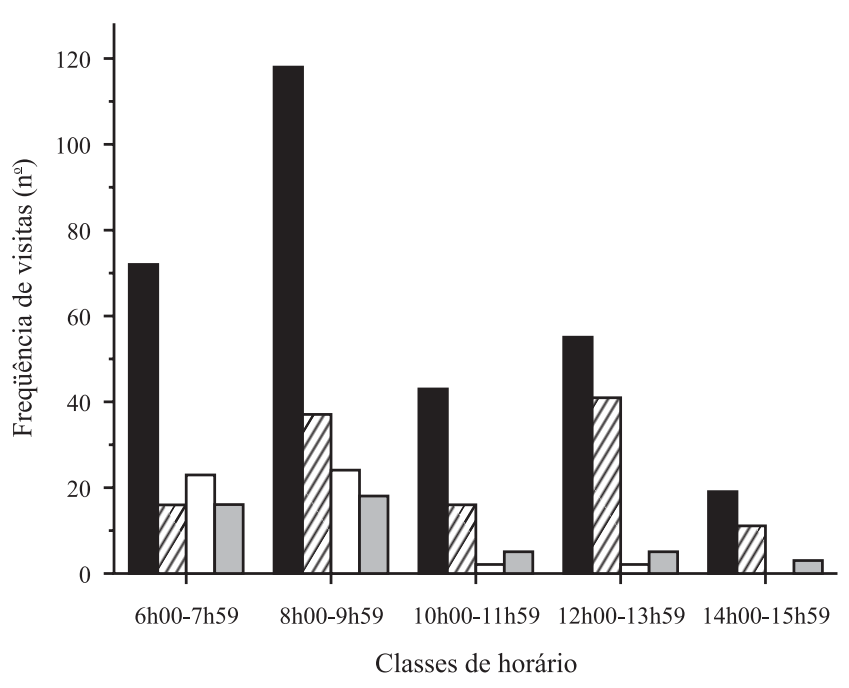

Figura 12. Frequiência de visitas registradas em flores de Dipteryx alata para todos os visitantes florais ( $\mathbf{\square})$, bem como para as abelhas Apis mellifera $(\mathbb{Z})$, Xylocopa suspecta $(\square)$ e Pseudaugochlora graminea $(\square)$ em cinco classes de horários.

Figure 12. Frequency of visits registered to flowers of Dipteryx alata of all floral visitors ( $\mathbf{0}$ ), and of Apis mellifera ( $\mathbb{Z}$ ), Xylocopa suspecta ( $\square$ ) and Pseudaugochlora graminea $(\square)$ in five different periods of the day.

lateralmente à flor, com as pernas apoiadas em botões/ flores próximas, empurrava as alas e as pétalas da quilha com as peças bucais, introduzindo a língua na entrada da câmara nectarífera. Ao adotar essa posição a abelha tocava as anteras com a cabeça (figura 7), na porção entre os olhos (22\%), ou não contatava anteras e estigma $(45,5 \%)$.

Indivíduos de A. mellifera e P. graminea observados sob estereomicroscópio apresentaram pólen na porção ventral do tórax (as duas espécies), cabeça e/ou na lateral do corpo (A. mellifera). Nos tratamentos para testar a eficiência de polinização (EP) de A. mellifera e $P$. graminea, a frutificação foi nula e baixa, respectivamente (tabela 1), sendo a EP de $P$. graminea semelhante à observada em condições naturais e após polinização cruzada $\left(\chi^{2}=0,91, P>0,05\right)$.

O comportamento de visita de Xylocopa suspecta foi semelhante ao observado para $P$. graminea, exceto por algumas variações descritas a seguir: a abelha pairava defronte a flor e ao pousar, agarrava-se à margem do lobo da sépala e/ou estandarte com o primeiro par de pernas. Ao adotar essa posição, a abelha apoiava o segundo e terceiro pares de pernas sobre botões, flores e/ou eixo da inflorescência ou dobrava o abdômen, apoiava o segundo par de pernas nas alas e o terceiro par agarrava- se à base do receptáculo (figura 9). Por apresentar maior dimensão corporal que $P$. graminea (tabela 3 ), após a liberação das estruturas sexuais das pétalas da quilha, as anteras e o estigma tocam a porção ventral de Xylocopa suspecta, entre cabeça e tórax, bem como o fêmur, locais onde foi verificada a presença de pólen. De modo geral, indivíduos de $X$. suspecta visitavam a maioria das flores de uma planta. Posteriormente, indivíduos desta espécie retornavam à planta após intervalos de 20 a 30 minutos.

Dentre as demais abelhas, Augochloropsis aff. cupreola apresentou tamanho corpóreo (tabela 3) e comportamento de visita semelhante ao de $P$. graminea . As abelhas de menor porte $(<0,8 \mathrm{~cm})$ (tabela 3 ) pousavam sobre e/ou lateralmente à flor, no estandarte ou ala. Em seguida posicionavam-se sobre alas e quilha e defronte o estandarte, no centro da flor, introduziam a língua na porção entre o estandarte e as alas, porém sem acionar o mecanismo de liberação das estruturas sexuais. Outras vezes introduziam a probóscide entre o estandarte e cálice sem contatar as demais pétalas. As vespas visitaram principalmente botões em pré-antese e ao visitar flores apresentaram comportamento semelhante ao descrito anteriormente para A. mellifera no item (ii), porém sem contatar anteras e estigma. As moscas visitaram somente flores desprovidas de alas, quilha e, às vezes, estandarte. Pousavam sobre o lobo do cálice ou limbo do estandarte, quando presente, posicionando-se sobre a bainha estaminal e pareciam lamber néctar na entrada da câmara nectarífera. Apesar de contatarem anteras e estigma com porção ventral do corpo, não foi observado pólen aderido nesta região.

As borboletas pousavam na flor, e com o primeiro e segundo pares de pernas apoiados nos lobos do cálice e/ou pétalas e o terceiro par em botões, flores e/ou eixo da inflorescência, introduziam a probóscide entre o estandarte e demais pétalas, sem promover o deslocamento das alas e quilha, não contatando as estruturas sexuais. Os beija-flores pairavam defronte ou lateralmente à flor e introduziam o bico na câmara nectarífera, sem acionar o mecanismo de liberação das estruturas sexuais das pétalas da quilha. Após três a cinco segundos visitavam outras flores ou abandonavam o local.

\section{Discussão}

Dipteryx alata apresenta padrão de floração anual e com regularidade intermediária (sensu Newstrom et al. 1994), pois floresce uma vez por ano, por até cinco meses. Padrão semelhante foi verificado para esta espécie no Maranhão (Bulhão \& Figueiredo 2002), bem como para D. panamensis (Pittier) Record \& Mell na Costa 
Rica (Perry \& Starrett 1980). A florada extensa de $D$. alata disponibiliza recurso (néctar) por longo período, o que pode favorecer a manutenção dos visitantes florais e/ou polinizadores nas áreas de ocorrência da espécie. Floração no início da estação chuvosa, como verificado em D. alata, é característica comum de espécies arbóreas de cerrado, sendo observada em comunidades de cerrado do Sudeste (Batalha \& Mantovani 2000) e Centro-Oeste (Oliveira \& Gibbs 2000, Lenza \& Klink 2006).

Apesar de D. alata apresentar padrão contínuo de frutificação (sensu Newstrom et al. 1994), a dispersão dos frutos ocorre principalmente na estação seca, concordando com o observado por Bulhão \& Figueiredo (2002) no Maranhão e por Pott \& Pott (1994) no Pantanal do Mato Grosso do Sul. A dispersão durante a estação seca torna esta espécie importante fonte de recurso para diversos grupos de animais silvestres (aves, morcegos, macacos) (Almeida et al. 1998), em um período em que geralmente há menor proporção de espécies zoocóricas dispersando os diásporos (Mantovani \& Martins 1988, Silberbauer-Gottsberger \& Gottsberger 1988, Batalha \& Mantovani 2000).

A redução na intensidade da floração e frutificação entre ciclos reprodutivos é registrada para outras espécies de Leguminosae, como Copaifera langsdorffii Desf. (Pedroni et al. 2002), bem como para espécies arbóreas de cerrado como, por exemplo, Qualea grandiflora Mart.-Vochysiaceae (Oliveira \& Gibbs 2000). A variação na intensidade de floração promove variação na produção de frutos e sementes, tornando diversa e instável sua disponibilidade entre anos, tanto para dispersores como para a coleta de sementes com fins comerciais. Este fato é relatado por coletores de sementes de D. alata em Mato Grosso do Sul, que registram oscilação na oferta de frutos de um ano para outro (João Ramão Belmonte Silva, dados não publicados).

As flores de $D$. alata possuem diversas características associadas à síndrome de melitofilia como antese diurna, presença de odor, plataforma de pouso, guias de recurso e zigomorfia (Faegri \& van der Pijl 1979, Endress 1994). Estas flores podem ser classificadas como tipo estandarte (sensu Faegri \& van der Pijl 1979) no qual as estruturas sexuais estão situadas na porção inferior da flor, de modo que a polinização é esternotríbica. São classificadas também como "flores de quilha" (Westerkamp 1997), pois as pétalas que formam a quilha recobrem androceu e gineceu, apresentando papel fundamental na liberação/ exposição das estruturas sexuais e, portanto, no mecanismo de polinização das flores.

Nas flores papilionáceas de D. alata foi registrado mecanismo de polinização intermediário entre os tipos explosivo e valvular (Westerkamp 1997), uma vez que após uma visita, as estruturas sexuais não são liberadas explosivamente da quilha (explosivo), porém não retornam totalmente a posição original, dentro da quilha (valvular), permanecendo parcialmente expostos fora desta estrutura. Neste mecanismo de polinização a carga polínica não é liberada durante uma única visita (explosivo), possibilitando retirada mais ou menos gradual do pólen em visitas subseqüentes. Entretanto, as estruturas sexuais ficam desprotegidas, o que pode facilitar a deposição adicional de pólen oriundo de autopolinização no estigma, reduzindo a área estigmática disponível para o pólen legítimo e contribuindo para a ocorrência de abortos (Bawa \& Buckley 1989). Em D. alata, a liberação das estruturas sexuais da quilha é resultante do posicionamento adequado do visitante floral, que precisa ter força e habilidade para pressionar o estandarte e forçar para baixo as alas e as pétalas da quilha para acessar a câmara nectarífera (Westerkamp 1997).

A presença de alas com superfície esculturada é caráter comum nas Papilionoideae, sendo a de D. alata do tipo lamelado (sensu Stirton 1981). Para D. alata as lamelas aparentemente atuam como local de produção de odor, pois apresentam osmóforos, bem como ponto de apoio para as abelhas A. mellifera durante visitas legítimas, porém não para as espécies de abelhas nativas. Stirton (1981) menciona esta última função para as esculturas das alas, fato não registrado e contestado por Christian Westerkamp (dados não publicados).

O reduzido volume de néctar produzido pelas flores de D. alata está de acordo com o observado para espécies de Papilionoideae com flores de pequeno tamanho (Kiill \& Drumond 2001). Em D. alata, a pequena quantidade de néctar por flor pode ser compensada pelo elevado número de flores abertas/dia, no pico de floração. Este fato pode ser favorável, pois induz os polinizadores a se deslocar entre flores e plantas para suprir suas necessidades energéticas (Frankie et al. 1983) e consequentemente, aumentar o fluxo polínico.

Dipteryx alata pode ser considerada autoincompatível pela ausência de frutificação após autopolinização manual, apesar do pequeno percentual de frutos obtidos após polinização cruzada, resultado comumente observado em outros gêneros de legumes arbóreos (Bawa \& Webb 1984, Seavey \& Bawa 1986), incluindo Dipteryx panamensis (Seavey \& Bawa 1986) onde foi utilizado elevado número de flores nos tratamentos.

Em D. alata parece ocorrer algum tipo de autoincompatibilidade de ação tardia (LSI) (Seavey \& Bawa 
1986), excetuando-se o tipo relacionado à inibição ovariana, pois em flores autopolinizadas parte dos tubos polínicos penetrou o óvulo, embora com menor velocidade que o observado para flores submetidas à polinização cruzada. Além disso, para $D$. alata a LSI parece ser corroborada pelo fato da maioria das flores autopolinizadas abortarem após uma semana, diferente do observado quando mecanismos de depressão endogâmica estão envolvidos, no qual pistilos autopolinizados e frutos jovens são abortados irregularmente após semanas ou meses (Carvalho \& Oliveira 2003).

A presença de película estigmática limita a autopolinização espontânea, pois parece impedir a aderência e hidratação do pólen, requisitos essenciais para a germinação (Heslop-Harrison \& Heslop-Harrison 1983). A ruptura da película depende de fatores mecânicos, principalmente visitantes florais e/ou polinizadores (Heslop-Harrison \& Heslop-Harrison 1983, Endress 1994). Em D. alata, como em outras Papilionoideae, a presença da película estigmática pode favorecer o aborto mais rápido de flores submetidas à autopolinização espontânea em relação às autopolinizadas manualmente, uma vez que impede a germinação dos grãos de pólen (Shivanna \& Owens 1989, Gibbs \& Sassaki 1998, Kiill \& Drumond 2001). A realização de autopolinização manual causa a ruptura da película possibilitando a aderência, hidratação e geminação dos grãos de pólen, os quais penetram os óvulos aparentemente retardando a abscisão dos pistilos em espécies com autoincompatibilidade de ação tardia, fenômeno registrado em $D$. panamensis, bem como em outras leguminosas e nas famílias Bombacaceae e Bignoniaceae (Seavey \& Bawa 1986, Gibbs \& Sassaki 1998, Gibbs et al. 2004).

A eficácia reprodutiva de $D$. alata foi baixa e provavelmente decorrente do elevado número de abortos em flores submetidas à polinização cruzada e em condições naturais. Bawa \& Webb (1984) e, posteriormente, Bawa \& Buckley (1989) relatam fato semelhante em espécies de Papilionoideae arbóreas e auto-incompatíveis e mencionam como principal causa a seleção sexual, mecanismo utilizado para regular a qualidade genética da progênie e menos freqüentemente, a disponibilidade de recursos maternos, ausência de polinização adequada e/ou pólen compatível. Em D. alata a polinização adequada é resultante principalmente da atividade da abelha Xylocopa suspecta, considerado o principal polinizador, pois visita elevado número de flores, de modo adequado e em curto período de tempo. Além disso, os indivíduos desta espécie são os primeiros a visitar as flores, concentrando as atividades na primeira metade da manhã e apresentam estratégia de forrageamento do tipo linha-de-captura, fundamental para a produção de frutos e sementes, pois promove o fluxo de pólen entre plantas (Frankie et al. 1983, Endress 1994). Entretanto, na subfamília Papilionoideae espécies de Xylocopa geralmente visitam flores de maior dimensão (Endress 1994). Para $D$. alata, a pequena dimensão da flor não restringiu o tamanho do polinizador uma vez que $X$. suspecta é abelha de grande porte $(>2,0 \mathrm{~cm}$ ) (sensu Frankie et al. 1983). Contribui para esse fato a disposição e a elevada quantidade de botões/flores na inflorescência, que fornecem plataforma de pouso e suporte adicional para visitantes de tamanho maior que a flor.

As abelhas $P$. graminea e A. mellifera, apesar da freqüência de visita relativamente alta, são consideradas polinizadores secundários, pois promovem principalmente polinização intra-planta, ineficaz para $D$. alata que parece ser auto-incompatível. Esse fato é evidenciado pela baixa eficiência de polinização registrada: 3,5 e zero, respectivamente (tabela 1). Apis mellifera, por apresentar comportamento de visita diversificado, atua também como pilhador do néctar das flores de $D$. alata em percentual relativamente elevado das visitas. Situação semelhante é relatada por Westerkamp (1991) para a alfafa (Medicago sativa L., Papilionoideae), na qual os indivíduos de A. mellifera deixam de visitar legitimamente as flores após "aprenderem", por tentativa e erro, a acessar o néctar sem contatar as estruturas sexuais. Segundo Westerkamp (1991) isto ocorre porque $A$. mellifera é exótica e não evoluiu com a espécie cuja flor está sendo visitada.

Com exceção da abelha Augochloropsis aff. cupreola, considerada polinizador eventual, os demais visitantes pilharam néctar nas flores de $D$. alata, pois não contataram as estruturas sexuais e/ou apresentaram baixa frequiência de visita. Nas flores de $D$. alata, a pilhagem do néctar é favorecida pelo desprendimento das pétalas, que expõe a entrada da câmara nectarífera.

Dipteryx alata apresenta variação na intensidade de floração e conseqüentemente de frutificação, tornando diversa e instável a produção de frutos e sementes entre anos, tornando necessário o estudo da fenologia reprodutiva de matrizes utilizadas na coleta de sementes com fins comerciais. Além disso, a espécie considerada auto-incompatível necessita de polinizadores que promovam o fluxo de pólen entre plantas, como a abelha solitária Xylocopa suspecta. Desta forma, a produção de sementes resulta da manutenção dos polinizadores efetivos (abelhas solitárias), cuja sobrevivência depende de fontes satisfatórias de recursos, bem como de locais e materiais adequados para nidificação (Silva \& Viana 2002). Abelhas A. mellifera não são bons polinizadores 
de $D$. alata, pois geralmente não realizam movimento entre plantas e em percentual elevado das visitas pilham néctar. Portanto, nas áreas de produção deve-se evitar o estabelecimento de colônias desta abelha, que compete por néctar com os polinizadores e abelhas nativas, uma vez que possui eficiente estratégia de forrageamento, bem como colônias constituídas por elevado número de indivíduos (Westerkamp 1991).

Agradecimentos - Dr. Sebastião Laroca (UFPR), Dr. André V. L. Freitas (UNICAMP), Dr. Gustavo Graciolli (UFMS) e MSc. Licléia da C. Rodrigues (UFMG) pela identificação das abelhas/vespas, borboletas, moscas e beija-flores, respectivamente; Dr. Gregório C. T. Ceccantini, por disponibilizar uso do microscópio de fluorescência do Laboratório de Anatomia Vegetal, Universidade de São Paulo; Luciano Lopes e Iara de Fátima Bressan pelo auxílio na observação dos tubos polínicos e adequação das técnicas; Augusto César de Aquino Ribas pelo auxílio nos tratamentos estatísticos; Rinaldo Duarte (Embrapa Gado de Corte) pelo fornecimento dos dados climáticos; Wellington Santos Fava, Caroline do Amaral Polido e Lidimila de Paula Tadei pelo auxílio no trabalho de campo; CAPES pela bolsa concedida à primeira autora; Programa de Pós Graduação em Biologia Vegetal da UFMS pelo auxílio financeiro.

\section{Referências bibliográficas}

ALMEIDA, S.P., PROENÇA, C.E.B., SANO, S.M. \& RIBEIRO, J.F. 1998. Cerrado: espécies vegetais úteis. CPAC-Embrapa, Planaltina.

ARROYO, M.T.K. 1981. Breeding systems and pollination biology in Leguminosae. In Advances in legume systematics (R.M. Polhill \& P.H. Raven, eds.). Royal Botanic Gardens, Kew, p.723-769.

BATALHA, M.A. \& MANTOVANI, W. 2000. Reproductive phenological patterns of cerrado plant species at the Pé de Gigante Reserve (Santa Rita do Passo Quatro SP, Brazil): a comparison between the herbaceous and woody floras. Revista Brasileira de Biologia 60:129-145.

BAWA, K.S. \& BUCKLEY, D.P. 1989. Seed:ovule ratios, selective seed abortion, and mating systems in Leguminosae. In Advances in legume biology. (C.H. Stirton \& J.L. Zarucchi, eds.). Monographs in Sistematic Botany from the Missouri Botanical Garden, New York, p.243-262.

BAWA, K.S. \& WEBB, C.J. 1984. Flower, fruit and seed abortion in tropical forest trees: implications for the evolution of paternal and maternal reproductive patterns. American Journal of Botany 71:736-751.

BERNARDELlO, G., AGUILAR, R. \& ANDERSON, G.J. 2004. The reproductive biology of Sophora fernandeziana (Leguminosae), a vulnerable endemic species from Isla Robinson Crusoe. American Journal of Botany 91:198-206.
BULHÃO, C.F. \& FIGUEIREDO, P.S. 2002. Fenologia de leguminosas arbóreas em uma área de cerrado marginal no nordeste do Maranhão. Revista Brasileira de Botânica 25:361-369.

CARVALHO, D.A. \& OLIVEIRA, P.E. 2003. Biologia reprodutiva e polinização de Senna sylvestris (Vell.) H. S. Irwin \& Barneby (Leguminosae, Caesalpinoideae). Revista Brasileira de Botânica 26:319-328.

DAFNI, A., KEVAN, P.G. \& HUSBAND, B.C. 2005. Practical pollination biology. Enviroquest Ltd., Ontario.

EMBRAPA - CNPGC. 1985. Boletim Agrometeorológico. Campo Grande, MS.

ENDRESS, P.K. 1994. Diversity and evolutionary biology of tropical flowers. Cambridge University Press, Cambridge.

FAEGRI, K. \& VAN DER PIJL, L. 1979. The principles of pollination ecology. Pergamon Press, Oxford.

FRANKIE, G.W., HABER, W.A., OPLER, P.A. \& BAWA, K.S. 1983. Characteristics and organization of the large bee pollination system in the Costa Rica dry forest. In Handbook of pollination biology (C.E. Jones \& R.J. Little, eds.). Van Nostrand Reinhold Company Inc., New York, p.411-448.

FOURNIER, L.A. 1974. Un método cuantitativo para lá medición de características fenológicas en árboles. Turrialba 24:422-423.

GIBBS, P.E. \& SASSAKI, R. 1998. Reproductive biology of Dalbergia miscolobium Benth. (LeguminosaePapilionoideae) in SE Brazil: the effect of pistilate sorting on fruit-set. Annals of Botany 81:735-740.

GIBBS, P.E., BIANCHI, M.B. \& TARODA RANGA, N. 2004. Effects of self-, chase and mixed self/crosspollinations on pistil longevity and fruit set in Ceiba species (Bombacaceae) with late-acting selfincompatibility. Annals of Botany 94:305-310.

HESLOP-HARRISON, J. \& HESLOP-HARRISON, Y. 1983. Pollen-stigma interaction in the Leguminosae: the organization of the stigma in Trifolium pratense L. Annals of Botany 51:571-583.

IPEF - INSTITUTO DE PESQUISAS E ESTUDOS FLORESTAIS. 2004. Preços de sementes de espécies florestais nativas e exóticas, Estado de São Paulo. Florestar Estatístico 16:72.

KIILL, L.H.P. \& DRUMOND, M.A. 2001. Biologia floral e sistema reprodutivo de Gliricidia sepium (Jacq.) Steud. (Fabaceae: Papilionoideae) na região de Petrolina, Pernambuco. Ciência Rural 31:597-601.

KÖPPEN, W. 1948. Climatología com un estudio de los climas de la tierra. Ed. Fondo Cultura Económica, Cuidad de México.

LENZA, E. \& KLINK, C.A. 2006. Comportamento fenológico de espécies lenhosas em um cerrado sentido restrito de Brasília, DF. Revista Brasileira de Botânica 29:627-638. 
LEPPIK, E.E. 1966. Floral evolution and pollination in Leguminosae. Annales Botanici Fennici 3:299-308.

LEWIS, G., SCHRIRE, B., MACKINDER, B. \& LOCK, M. 2005. Legumes of the world. Royal Botanic Gardens, Kew.

LOPEZ, J., RODRIGUEZ-RIANO, T., OLIVENCIA, O.A., DEVESA, J.A. \& TRINIDAD, R. 1999. Pollination mechanisms and pollen-ovule ratios in some Genisteae (Fabaceae) from Southwestern Europe. P1ant Systematics and Evolution 216:23-47.

MANTOVANI, W. \& MARTINS, F.R. 1988. Variações fenológicas das espécies do cerrado da Reserva Biológica de Moji Guaçu, Estado de São Paulo. Revista Brasileira de Botânica 11:101-112.

MARTIN, F.W. 1959. Staining and observing pollen tubes in the style by means of fluorescence. Stain Technology 34:125.

NEWSTROM, L.E., FRANKIE, G.M. \& BAKER, H.G. 1994. A new classification for plant phenology based on flowering patterns in lowland tropical rain forest trees at La Selva. Biotropica 2:141-159.

OLIVEIRA, P.E. \& GIBBS, P.E. 2000. Reproductive biology of woody plants in a cerrado community of Central Brazil. Flora 195:311-329.

PEDRONI, F., SANCHES, M. \& SANTOS, F.A.M. 2002. Fenologia da copaíba (Copaifera langsdorffii Desf. Leguminosae, Caesalpinoideae) em uma floresta semidecídua no sudeste do Brasil. Revista Brasileira de Botânica 25:183-194.

PÉREZ-BAÑóN, C., JUAN, A., PETANIDOU, T., MARCOS-GARCIA, M.A. \& CRESPO, M.B. 2003. The reproductive ecology of Medicago citrina (Font Quer) Greuter (Leguminosae): a bee-pollinated plant in mediterranean islands where bees are absent. Plant Systematics and Evolution 241:29-46.

PERRY, D.R. \& STARRETT, A. 1980. The pollination ecology and blooming strategy of a neotropical emergent tree, Dipteryx panamensis. Biotropica 12:307-313.

POTT, A. \& POTT, V.J. 1994. Plantas do pantanal. CPAPEmbrapa, Brasília.

SCHIVANNA K.P \& OWENS, S.J. 1989. Pollen-ovule interactions (Papilionoideae). In Advances in legume biology. (C.H. Stirton \& J.L. Zarucchi, eds.). Monographs in Systematic Botany from the Missouri Botanical Garden, New York, p.29:157-182.
SECRETARIA DA CONSERVAÇÃO SOBREDIVERSIDADE BIOLÓGICA. 2006. Estratégia global para a conservação de plantas. Instituto de pesquisas Jardim Botânico do Rio de Janeiro, Rio de Janeiro.

SEAVEY, S.R. \& BAWA, K.S. 1986. Late-acting selfincompatibility in angiosperms. Botanical Review 52:152-219.

SILBERBAUER-GOTTSBERGER, I. \& GOTTSBERGER, G. 1988. A polinização de plantas do cerrado. Revista Brasileira de Biologia 48:651-663.

SILVA, A.K. \& EGITO, M. 2005. Rede de comercialização solidária de agricultores familiares e extrativistas do cerrado: um novo protagonismo social. Agriculturas 2:14-16.

SILVA, F.O. \& VIANA, B.F. 2002. Distribuição de ninhos de abelhas Xylocopa (Hymenoptera: Apidae) em uma área de dunas litorâneas. Neotropical Entomology 31:661-664.

SOBREVILA, C. \& ARROYO, M.T.K. 1982. Breeding systems in a montane tropical cloud forest in Venezuela. Plant Systematics and Evolution 140:19-37.

SPEARS, E.E. 1983. A direct measure of pollinator effectiveness. Oecologia 57:196-199.

STIRTON, C.H. 1981. Petal sculpturing in papilionoid legumes. In Advances in legume systematics (R.M. Polhill \& P.H. Raven, eds.). Royal Botanic Garden, Kew, p.771-788.

STRITTMATTER, C.G.D. 1973. Nueva técnica de diafanizacion. Boletin de la Sociedad Argentina de Botanica 15:126-129.

THUM, A.B. \& COSTA, E.C. 1998/1999. Entomofauna visitante das inflorescências de Syagrus romanzoffiana (Cham.) Glassm. (Palmae). Revista da Faculdade de Zootecnia, Veterinária e Agronomia de Uruguaiana 5/ 6:43-47.

VELTEN, S.B. \& GARCIA, Q.S. 2005. Efeitos da luz e da temperatura na germinação de sementes de Eremanthus (Asteraceae), ocorrentes na serra do Cipó, MG, Brasil. Acta Botanica Brasilica 19:753-761.

WESTERKAMP, C. 1991. Honeybees are poor pollinators - why? Plant Systematics and Evolution 177:71-75.

WESTERKAMP, C. 1997. Keel blossoms: bee flowers with adaptations against bees. Flora 192:125-132.

ZAR, J.H. 1999. Biostatistical analysis. Prentice-Hall, New Jersey. 